\title{
IAMJ
}

INTERNATIONAL

AYURVEDIC

MEDICAL JOURNAL

Research Article

ISSN: 2320-5091

Impact Factor: 6.719

\section{AN EXPERIMENTAL EVALUATION OF Andrographis macrobotrys Nees., A FOLK MEDICINAL PLANT FOR ANALGESIC ACTION IN WISTAR ALBINO RATS AND SWISS ALBINO MICE- IN VIVO STUDY}

\author{
Ranjitha $S^{1}$, Chandrakanth Bhat ${ }^{2}$ \\ ${ }^{1}$ PG Scholar, Department of Dravyaguna, MIAMS, Manipal- 576104, Udupi district, Karnataka, India \\ ${ }^{2}$ HOD and Professor, Department of Dravyaguna, MIAMS, Manipal- 576104, Udupi district, Karnataka, India
}

Corresponding Author: abhi.rymec@gmail.com

https://doi.org/10.46607/iamj1409082021

(Published Online: August 2021)

Open Access

(C) International Ayurvedic Medical Journal, India 2021

Article Received: 29/07//2021 - Peer Reviewed: 10/08/2021 - Accepted for Publication: 11/08/2021

Check for updates

\section{ABSTRACT}

Background and objective: In India Medicinal plants have a wide range of uses in folk medical practice. Andrographis macrobotrys Nees. belongs to Acanthaceae family is found in South India and Srilanka. It is in folk use by tribes in Kerala to treat muscle pain, snakebite, fever, and jaundice. The present research work aims to evaluate test drug $s$ for their analgesic action. Methods: The detailed review of the test drug and disease Pain has been carried out. An animal experimental study has been carried out to assess the analgesic activity of the drug by acetic acidinduced writhing movement in Swiss albino mice and Eddy's hot plate method in Wistar albino rats. Results and conclusion: The test drug showed analgesic action with Swarasa of leaves and Kashaya of the whole plant. The drug was found to have both peripheral and central analgesic action.

Keywords: Andrographis macrobotrys Nees., Acanthaceae, folk medicinal plant, Analgesic action 


\section{INTRODUCTION}

Since ancient times, human beings are utilizing plants for many purposes all around the world. From Vedic literature to recent texts of Ayurveda including Puranas, Samhitas and Nighantus, single-drug therapy is explained as a popular method of management of various diseases. Ayurveda is a research-oriented ancient medical science, Charaka explains the importance of research especially Drug research in Vimana sthana ${ }^{l}$. The extinction of medicinal herbs is rapidly increasing due to various reasons, fortunately, folk herbs are densely found in India which are to be explored scientifically. Pain is an unpleasant sensory and emotional experience associated with actual or potential tissue damage or described in terms of such damage ${ }^{2}$. Analgesics are drugs that relieve pain without causing loss of consciousness ${ }^{2}$. Even if there is a wide experience in the use of non-opioid (NSAIDs) and opioid analgesics, they continue to capture attention with safety concerns and with potential risks. Ethno-medicinal studies can contribute the beginning step for the development of a new drug concept. Andrographis macrobotrys Nees. is one such ethnomedicinal plant in South India and Srilanka ${ }^{3}$. It is an erect, stout herb of the Acanthaceae family is used as folk medicine by tribes in Kerala for the treatment of snakebite, diarrhoea, muscle pain ${ }^{4}$, fever, jaundice, liver disorders and skin diseases ${ }^{5}$. The above drug is not explored as medicine and very little work has been carried out so far. Hence an experimental study is taken for its analgesic action through an in-vivo study.

\section{Materials and Methods}

Plant collection and authentication: The drug $A n$ drographis macrobotrys Nees., the whole plant was collected from Bailur and nearby places in Udupi district, surrounding ALN Rao Ayurvedic medical college campus in Koppa and is authenticated by M. Radhakrishna Rao, Visiting Professor of Botany, ALN Rao memorial Ayurvedic College, Koppa. For the preparation of Swarasa plant was initially identified and cultivated in MIAMS Herbal Garden and was freshly collected.

Selection of animals for the experiment - Healthy 24 Swiss albino mice of either sex, weighing between 30-
50 gm and 24 Wistar albino rats of either sex, weighing between 200-250 gm were obtained from the Animal house SDM centre for research in Ayurveda and allied sciences, Udupi, to conduct the animal experiment.

\section{Animal housing}

The mice and rats were housed in polypropylene cages with food, water, environmental temperature, humidity and light and dark cycle. Mice and rats were with. They were acclimatized to the laboratory conditions for at least one week before using them for the experimental study. Mice and rats with pathological conditions, which are pregnant or subjected to other experiments are excluded.

\section{Animal ethical committee clearance}

The experimental study was carried out at the S.D.M center for research in Ayurveda and allied health sciences, Kuthpady, Udupi, and Karnataka. Approval no. SDMCRA/IAEC/M-DG-17 by 26/03/2018.

\section{Acute toxicity study of test drug}

An acute toxicity study was conducted to determine the $\mathrm{LD}_{50}$ dose of Andrographis macrobotrys Nees., Swarasa. Drug was administered orally at different dose level in 5 different rats in $175 \mathrm{mg} / \mathrm{kg}, 550 \mathrm{mg} / \mathrm{kg}$, $2000 \mathrm{mg} / \mathrm{kg}$ and $2000 \mathrm{mg} / \mathrm{kg}$. All animals were observed at 1/2, 1, 2, 3, 4, 24 and $48 \mathrm{hrs}$ dosing and thereafter daily once for mortality during the entire period of 15 days study. The maximum tolerated dose was calculated by employing OECD 425 guidelines with AOT software. The $\mathrm{LD}_{50}$ value was found to be less than $2000 \mathrm{mg} / \mathrm{kg}$.

\section{Analgesic study of test drug}

Preparation of Drug used and its route of administration

Group I Water control

Group II Diclofenac sodium tablet $50 \mathrm{mg}$

Diclofenac sodium tablet weighing $50 \mathrm{mg}$ was finely powdered and made into a suspension by adding $10 \mathrm{ml}$ distilled water and administered according to $0.1 \mathrm{mg} / 100 \mathrm{ml}$ body weight.

Group III (Trial group I) - At SDM research centre for Ayurveda and allied sciences, Udupi- Kashaya(decoction) was prepared from coarse powder of the 
whole plant of trial drug Andrographis macrobotrys Nees., adding water in the ratio $1: 8$ as mentioned in Sharangadhara Samhita for hard substances, boiled and reduced to $1 / 4^{\text {th }}$ part of it $^{6}$.

Group IV (Trial group II) - Swarasa (juice) was prepared with fresh leaves of trial drug Andrographis macrobotrys Nees., at SDM research centre for Ayurveda and allied sciences, Udupi

\section{Methodology}

Analgesic action

\section{Acetic acid-induced writhing movement test}

Table 1: Grouping of animals for Acetic acid-induced writhing movement test

\begin{tabular}{|l|l|l|}
\hline S. no & Grouping & Study \\
\hline 1. & Group I (control group) & Normal filter water \\
\hline 2. & Group II (Standard group) & Standard drug Diclofenac \\
\hline 3. & Group III (Trial group I) & Kashaya of Andrographis macrobotrys Nees., whole plant \\
\hline 4. & Group IV (Trial group II) & Swarasa of Andrographis macrobotrys Nees., leaves \\
\hline
\end{tabular}

Dose fixation Based on PAGET AND BARNES formula involving body surface area constant for Swiss albino mice and human dose (H.D) formula is H.D $\times$ $0.0026 \times 50$

Test drug: Kashaya of the whole plant of Andrographis macrobotrys Nees.,

Human dose $=96 \mathrm{ml}$

Therefore, Mice dose $=12.48 \mathrm{ml} / \mathrm{kg}$ body weight $=0.01248 \mathrm{ml} / \mathrm{gm}$ body weight

Test drug: Swarasa of leaves of Andrographis macrobotrys Nees.,

Human dose $=24 \mathrm{ml}$

Therefore, Mice dose $=3.12 \mathrm{ml} / \mathrm{kg}$ body weight $=$ $0.00312 \mathrm{ml} / \mathrm{gm}$ body weight

Experimental Procedure:

Mice of either sex are selected, weighed, and grouped into 4 groups of 6 mice each. To Group I normal filter
- Diclofenac and trial drugs are administered through the oral route with the help of a specific feeding syringe to mice and rats.

Chemical materials- 6\% Acetic acid is used for intraperitoneal injection with the help of a $1 \mathrm{ml}$ syringe to induce pain.

\section{Eddy's hot plate method}

Table 2: Grouping of animals for Eddy's hot plate method

\begin{tabular}{|l|l|l|}
\hline S1 no & Grouping & Study \\
\hline 1. & Group I (control group) & Normal filter water \\
\hline 2. & Group II (Standard group) & Standard drug Diclofenac \\
\hline 3. & Group III (Trial group I) & Kashaya of Andrographis macrobotrys Nees., whole plant \\
\hline 4. & Group IV (Trial group II) & Swarasa of Andrographis macrobotrys Nees., leaves \\
\hline
\end{tabular}


Dose fixation Based on PAGET AND BARNES formula involving body surface area constant for Wistar Albino rat and human dose (H.D) formula is Human dose $\times 0.018 \times 5$

Test drug: Kashaya of the whole plant of Andrographis macrobotrys Nees.,

Human dose of Kashaya $=96 \mathrm{ml}$

Therefore, Rat dose $=8.64 \mathrm{ml} / \mathrm{kg}$ body weight $=$ $0.00864 \mathrm{ml} / \mathrm{gm}$ body weight

Test drug: Swarasa of leaves of Andrographis macrobotrys Nees.,

Human dosage of Swarasa $=24 \mathrm{ml}$

Therefore, Rat dose $=2.16 \mathrm{ml} / \mathrm{kg}$ body weight= $0.00216 \mathrm{ml} / \mathrm{gm}$ body weight

\section{Experimental procedure}

Group of mice of either sex is taken weighed, and dosage is calculated. To Group I normal filter water was administered to serve as control; Group II was taken as standard and administered with the standard drug Diclofenac in a single dose for 3 consecutive days; Group
III was administered with Kashaya of Andrographis macrobotrys Nees., whole plant in a single dose for 8 consecutive days; Group IV was administered with Swarasa of Andrographis macrobotrys Nees., leaves in a single dose for 8 consecutive days. Eddy's hot plate which is commercially available consists of an electrically heated surface. The temperature is controlled at 55 to $56^{\circ} \mathrm{C}$. The animals are kept on a hot plate and the time until either licking or jumping occurs is recorded by a stopwatch. Latency is recorded after 10, 20, 30, 40 and 60 min following oral administration of the respective drug to each group of rats STATISTICAL ANALYSIS

The values noted were expressed as MEAN \pm SEM (Standard Error of Mean). The data were analysed by one-way ANOVA followed by Dunnet's multiple comparison t-test as a post hoc test. Graph pad in stat software is used for this purpose. If $\mathrm{p} \leq 0.05$ it is considered statistically significant. Accordingly, level of significance was noted and interpreted.

\section{RESULTS}

\section{Acetic acid-induced writhing movement}

Table 3: Effect of Andrographis macrobotrys Nees., on latency period of writhing movement

\begin{tabular}{|l|l|l|}
\hline Group & The latency period (in min) & \% change \\
\hline Control & $0.61 \pm 0.18$ & \\
\hline Standard & $5.44 \pm 2.83$ & $791 \uparrow$ \\
\hline Kashaya & $3.04 \pm 1.52$ & $398 \uparrow$ \\
\hline Swarasa & $3.71 \pm 1.95$ & $508 \uparrow$ \\
\hline
\end{tabular}

\section{Data: MEAN \pm SEM}

The data shows there was an increase in latency period of writhing movement in standard, Kashaya and Swarasa groups when compared to the control group, the observed increase was found to be statistically nonsignificant.

Table 4: Effect of Andrographis macrobotrys Nees., on the total number of writhing

\begin{tabular}{|l|l|l|}
\hline Group & Total number of writhing (in $\min )$ & $\%$ change \\
\hline Control & $14.6 \pm 2.61$ & \\
\hline Standard & $4.16 \pm 1.01^{* *}$ & $71.5 \downarrow$ \\
\hline Kashaya & $8.7 \pm 2.50$ & $40.4 \downarrow$ \\
\hline Swarasa & $4 \pm 1.52^{* *}$ & $72.60 \downarrow$ \\
\hline
\end{tabular}

Data: MEAN \pm SEM **P $<0.01$ 
The data shows there was a decrease in the total number of writhing movements in the standard and Swarasa groups when compared to the control group, the observed decrease was found to be statistically very significant. There was a decrease in the total number of writhing movements in Kashaya group when compared to the control group, the observed decrease was found to be statistically non-significant.

Table 5: Effect of Andrographis macrobotrys Nees., on writhing at peak (10-15 min)

\begin{tabular}{|l|l|l|}
\hline Group & Writhing at Peak (in min) & $\%$ Change \\
\hline Control & $3.33 \pm 0.42$ & \\
\hline Standard & $0.66 \pm 0.33^{* *}$ & $80.18 \downarrow$ \\
\hline Kashaya & $1.71 \pm 0.83$ & $48.64 \downarrow$ \\
\hline Swarasa & $0.16 \pm 0.16^{* *}$ & $95.19 \downarrow$ \\
\hline
\end{tabular}

\section{Data: MEAN \pm SEM $* * \mathbf{P}<0.01$}

The data shows there was a decrease of writhing movement in standard and Swarasa groups when compared to the control group, the observed decrease was found to be statistically very significant. There was a decrease in writhing movement in Kashaya group when compared to the control group, the observed decrease was found to be statistically non-significant

\section{Eddy's hot plate method}

Table 6: Effect of Andrographis macrobotrys Nees., on the initial response on a hot plate

\begin{tabular}{|l|l|l|}
\hline Group & Initial response (in a sec) & \% Change \\
\hline Control & $5.49 \pm 0.43$ & \\
\hline Standard & $13.72 \pm 2.14 * *$ & $149.9 \uparrow$ \\
\hline Kashaya & $9.51 \pm 1.11$ & $73.2 \uparrow$ \\
\hline Swarasa & $7.5 \pm 1.41$ & $36.6 \uparrow$ \\
\hline
\end{tabular}

Data: MEAN \pm SEM **P $<0.01$

The data shows there was an increase in time taken for an initial response on a hot plate in the standard group when compared to the control group, the observed increase was found to be statistically very significant.
There was an increase in time taken for an initial response on a hot plate in Kashaya and Swarasa groups when compared to the control group, the observed increase was found to be statistically non-significant

Table 7: Effect of Andrographis macrobotrys Nees., on the response at $10 \mathrm{~min}$ on a hot plate

\begin{tabular}{|l|l|l|}
\hline Group & Response at $10 \mathrm{~min}$ (in a sec) & \% Change \\
\hline Control & $6.74 \pm 0.79$ & \\
\hline Standard & $21.02 \pm 2.89^{* *}$ & $211.86 \uparrow$ \\
\hline Kashaya & $11.47 \pm 3.46$ & $70.17 \uparrow$ \\
\hline Swarasa & $12.12 \pm 1.93$ & $79.82 \uparrow$ \\
\hline
\end{tabular}

Data: MEAN \pm SEM **P $<0.01$

The data shows there was an increase in time taken for a response on a hot plate at $10 \mathrm{~min}$ in the standard group when compared to the control group, the observed increase was found to be statistically very sig- nificant. There was an increase in time taken for a response on a hot plate at 10min in Kashaya and Swarasa groups when compared to the control group, the observed increase was found to be statistically nonsignificant 
Table 8: Effect of Andrographis macrobotrys Nees., on the response at 20min on a hot plate

\begin{tabular}{|l|l|l|}
\hline Group & Response at 20min (in a sec) & \% change \\
\hline Control & $9.32 \pm 1.74$ & \\
\hline Standard & $12.25 \pm 2.19$ & $31.43 \uparrow$ \\
\hline Kashaya & $19.25 \pm 2.11^{* *}$ & $108.55 \uparrow$ \\
\hline Swarasa & $16.05 \pm 1.91^{*}$ & $72.21 \uparrow$ \\
\hline
\end{tabular}

\section{Data: MEAN \pm SEM $* * \mathbf{P}<0.01 * \mathbf{P}<0.05$}

The data shows there was an increase in time taken for a response on a hot plate at $20 \mathrm{~min}$ in the standard group when compared to the control group, which was found to be statistically non-significant. There was an increase in time taken for a response on a hot plate at $20 \mathrm{~min}$ in the Kashaya group when compared to the control group, which was found to be statistically very significant. There was an increase in time taken for a response on a hot plate at 20min in Swarasa group when compared to the control group, which was found to be statistically significant

Table 9: Effect of Andrographis macrobotrys Nees., on the response at 30min on a hot plate

\begin{tabular}{|l|l|l|}
\hline Group & Response at 30min (in a sec) & \% change \\
\hline Control & $8.82 \pm 0.87$ & \\
\hline Standard & $24.01 \pm 7033$ & $172.22 \uparrow$ \\
\hline Kashaya & $28.31 \pm 5.71$ & $220.97 \uparrow$ \\
\hline Swarasa & $16.83 \pm 5.60$ & $90.81 \uparrow$ \\
\hline
\end{tabular}

\section{Data: MEAN \pm SEM}

The data shows there was an increase in time taken for a response on a hot plate at $30 \mathrm{~min}$ in standard, Kashaya and Swarasa groups when compared to the control group, the observed increase was found to be statistically non-significant.

Table 10: Effect of Andrographis macrobotrys Nees., on the response at 40min on a hot plate

\begin{tabular}{|l|l|l|}
\hline Group & Response at 40min (in a sec) & \% change \\
\hline Control & $7.45 \pm 1.05$ & \\
\hline Standard & $24.02 \pm 7.11$ & $222.41 \uparrow$ \\
\hline Kashaya & $34.76 \pm 7.11^{* *}$ & $366.57 \uparrow$ \\
\hline Swarasa & $11.89 \pm 0.86$ & $59.59 \uparrow$ \\
\hline
\end{tabular}

Data: MEAN \pm SEM $* * P<0.01$

The data shows there was an increase in time taken for a response on a hot plate at $40 \mathrm{~min}$ in standard and Swarasa groups when compared to the control group, the observed increase was found to be statistically nonsignificant. There was an increase in time taken for a response on a hot plate at 40min in Kashaya group when compared to the control group, the observed increase was found to be statistically very significant.

\section{DISCUSSION}

An experimental study was conducted at S.D.M. Centre for Research in Ayurveda and Allied Sciences, Udupi. The animal experiment was conducted after getting prior permission from the Institutional Animal Ethical Committee.

Analgesic activity: Analgesic activity of test drug Andrographis macrobotrys Nees., is assessed by employing two methods of animal experimentation in this 
study. Acetic acid-induced writhing movement in Swiss Albino mice is employed to assess analgesic effect produced by peripheral mechanism and Hot plate method in Wistar albino rat is employed to assess analgesic effect through a central mechanism.

\section{Acetic acid-induced writhing movement}

Table 11: Concluding result on the effect of Andrographis macrobotrys Nees., Kashaya and Swarasa on parameters of Acetic Acid induced writhing movement:

\begin{tabular}{|l|l|l|l|}
\hline & Standard & Kashaya & Swarasa \\
\hline Latency & NSI & NSI & NSI \\
\hline Total number of writhing & SD & NSD & SD \\
\hline Peak (10-15 min) & SD & NSD & SD \\
\hline
\end{tabular}

NSI- Non-significant increase, SD- Significant decrease, NSD- Non-significant decrease

The acetic acid-induced abdominal writhing has been used as a screening tool for assessing analgesic or antiinflammatory agents. This model is used as an antinociceptive model for opioids and is commonly employed as a visceral inflammatory model. Pain is induced by the injection of irritants into the peritoneal cavity of mice. Mice are observed for the reaction of animals which reacts with a characteristic stretching behaviour called writhing (stretch, tension to one side, extension of hind legs, contraction of abdomen or twisting of trunk). Analgesic activity of the test drug is inferred from a decrease in the frequency of writhing. Acetic acid-induced constriction is considered to be a nonselective nociceptive model, as it acts indirectly by inducing the release of endogenous mediators which stimulate the nociceptive neurons that are sensitive to nonsteroidal anti-inflammatory drugs, narcotics and other centrally active drugs. In this study, analysing the results shows, increase in latency period in the Eddy's hot plate method

Table 12: Consolidated statement on the percentage change of pain threshold at different time intervals on the administration of Andrographis macrobotrys Nees, Kashaya and Swarasa

\begin{tabular}{|l|l|l|l|}
\hline Time interval & Standard & Kashaya & Swarasa \\
\hline $10 \mathrm{~min}$ & SI & NSI & NSI \\
\hline $20 \mathrm{~min}$ & NSI & SI & SI \\
\hline $30 \mathrm{~min}$ & NSI & NSI & NSI \\
\hline $40 \mathrm{~min}$ & NSI & SI & NSI \\
\hline $60 \mathrm{~min}$ & NSI & NSI & NSI \\
\hline
\end{tabular}

SI- Significant increase NSI- Non-significant increase, SD- Significant decrease NSD- Non-significant decrease 
The hot plate method is employed to assess the analgesic which acts through central mechanisms by observing paw licking and jump response to assess the effect of the test drug on neurogenic pain. In the present study, the hot plate method was employed hence the analgesic activity evaluation for the central analgesic type of activity.

Careful analysis of the results indicates that, When the Standard drug administered group is compared with the control, significant elevation in pain threshold was observed at 10min but non-significant increase in pain threshold at 20,30, 40,60min. This shows that the standard drug has analgesic action for a lesser duration. At 20min, the pain threshold was found to be elevated significantly in both Kashaya and Swarasa groups when compared with the control group. At 40min, the Pain threshold was found to be significant elevation only in Kashaya group when compared to the control. Elevation of pain threshold is observed in standard and both the test drug groups when compared to control group. This indicates the presence of Central analgesic activity in both Kashaya of whole plant and Swarasa of leaves of test drug Andrographis macrobotrys Nees, At 10, 30 and 60 min increase in pain threshold in Kashaya and Swarasa groups was statistically non-significant which can be considered as moderate action of the drug. The probable mechanism of action of analgesic effect observed and chemical reactions responsible for the analgesia is needed to be discussed to interpret the mode of action of the test drug. Pain is interpreted and perceived in the brain. In central analgesic action, any drug which produces modulation inactivity of the opioid receptors or increase in formation and release of endogenous opiates will produce an analgesic effect. Transmission of pain impulses from site to CNS can be controlled at the Spinal level or by presynaptic inhibition of dorsal nerve ending through specific $\mathrm{GABA}_{\mathrm{A}}$ receptors. Intracranial electrical stimulation of certain areas inhibits pain while touch, pressure and temperature sensation remain intact. In the above procedure, Eddy's hot plate method is selective for the study on Central analgesic activity and peripheral analgesic mechanisms are not involved. Based on this, it can be inferred that test drug Andrographis macrobotrys Nees., have a central analgesic effect. Further analysis of results obtained from the above study gives clarity that Kashaya group is giving the analgesic action for a longer duration than Swarasa group. To understand the action of drug Andrographis macrobotrys Nees., in chronic pain on the central nervous system and to recognize mechanisms for early and delayed response further studies can be undertaken.

\section{Probable mode of action}

According to the observation and analysis of the present study, it is confirmed that test drug Andrographis macrobotrys Nees., have analgesic action. The analgesic action of Andrographis macrobotrys Nees. maybe due to the presence of Steroids, tannin, triterpenoid, flavonoid and Phenols. A recent study shows the presence of diterpenoid Neoandrographolide in leaves of Andrographis macrobotrys Nees., which may be responsible for its analgesic action. Andrographis macrobotrys Nees. has got Tiktha rasa (bitter taste), Kashaya Anurasa (astringent secondary taste), Sheetha Virya (cold potency) and Katu Vipaka (pungent taste after digestion) which might be responsible factors for its analgesic activity. Other than this even Prabhava (potency) of Andrographis macrobotrys Nees., can be the responsible factor for its analgesic action. Swarasa of Andrographis macrobotrys Nees., showing the best analgesic action in acetic acid-induced writhing movement and Kashaya showed the best action in the hot plate method. To elicit proper mechanism researchers can take up molecular level study. 


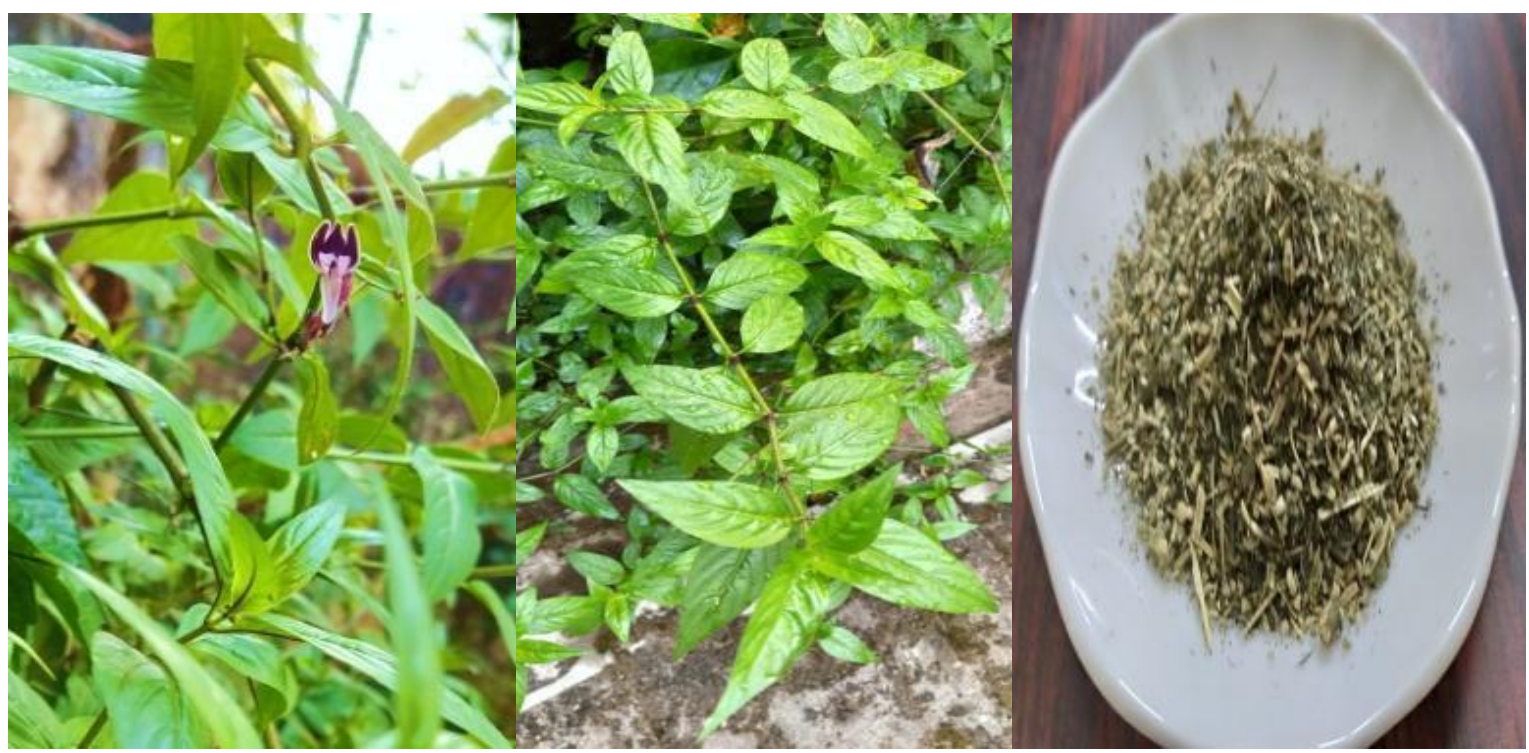

Fig 1 \& 2 - Plant Andrographis macrobotrys Nees.,

Fig no. 3 Coarse powder of Andrographis macrobotrys Nees.
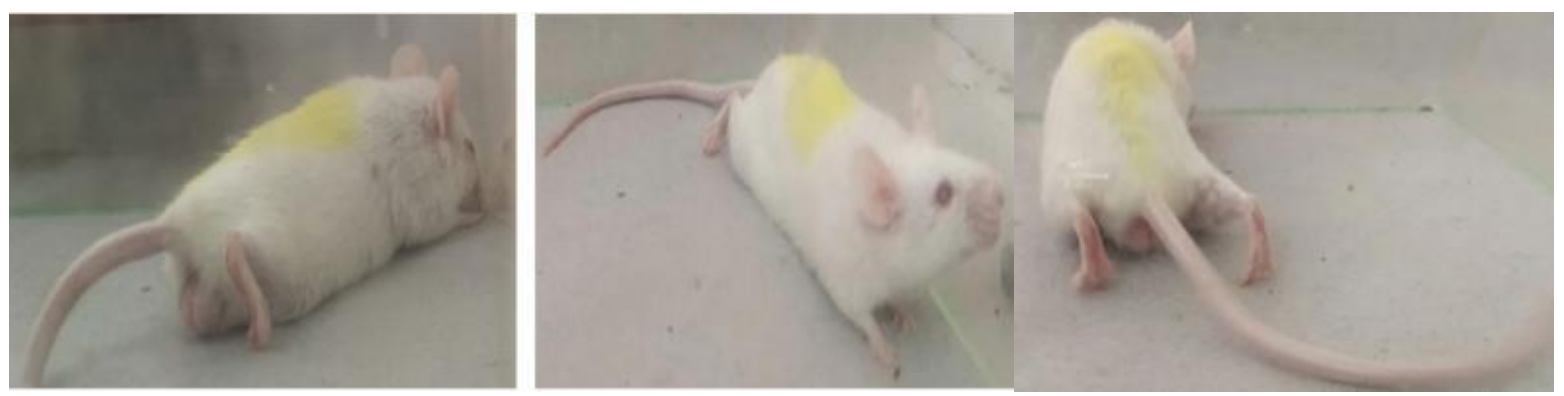

Fig 4, 5 \& 6 Writhing and hind limb extension shown by Swiss albino mice in acetic acid-induced writhing movement study.

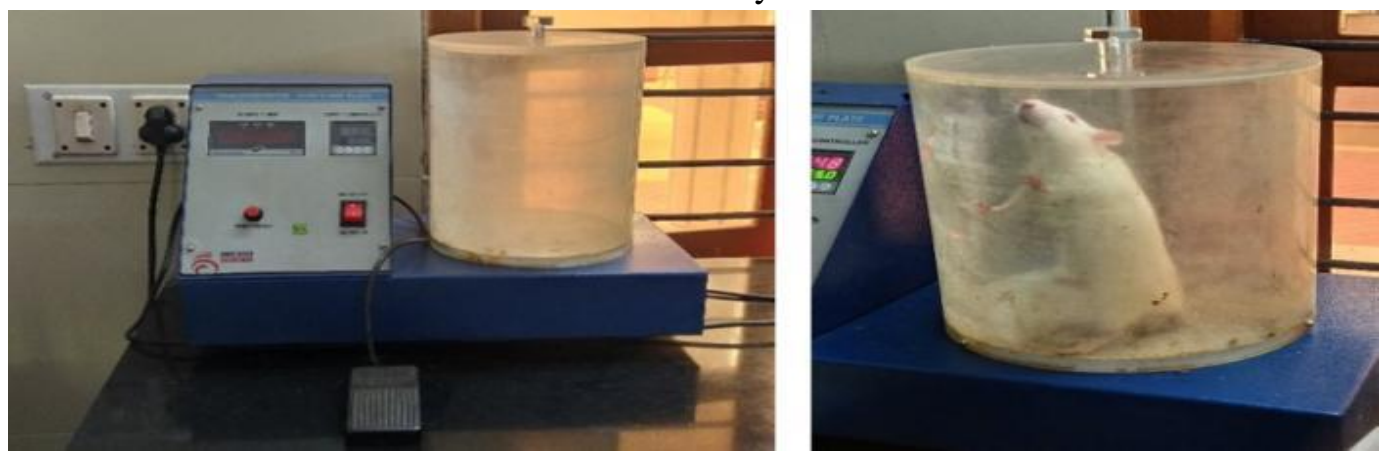

Fig $7 \& 8$ show Instrument Eddy's hot plate and Wistar albino rat over hot plate showing jumping and paw licking

\section{CONCLUSION}

Andrographis macrobotrys Nees. is used by tribes in the treatment of muscle pain, fever, Jaundice etc. To determine the Analgesic activity of the drug, an experimental study was carried out in 2 different models. Acetic acid-induced writhing movement is selective for the peripheral analgesic mechanisms and Eddy's hot plate method for its action on the central nervous system. Acetic acid-induced writhing movement on Swiss Albino mice and Eddy's hot plate method on Wistar Albino rat reveals that Andrographis macrobotrys Nees., have analgesic action by both Swarasa of leaves and Kashaya of the whole plant. To be specific, Swarasa shown the best analgesic activity in 
Acetic acid-induced writhing movement and Kashaya shown the best analgesic activity in Eddy's hot plate method. To elicit proper mechanism researchers can take up molecular level study.

\section{REFERENCES}

1. Agnivesha, Charaka Samhita, Vimana Sthana 86-87, reprint-2017, Chaukhambha publications, New Delhi, Pg no- 274-275, 61, 616-617.Pp- 738

2. Satoskar. R, Bhandarkar. S.D, Ainapure. S.S, Pharmacology and Pharmacotherapeutics, Edition $-17^{\text {th }}$, reprint 2002 Mumbai, Popular Prakashan Private Ltd. Page no: 135-137, 155-156, Pp: 1111.

3. Bhat K Gopalkrishna, Flora of Udupi, Published in 2003, Indian naturalist, Udupi, Pg no-470, Pp-913

4. Udayan.P. S and Indira Balachandran. Medicinal plants of Arya Vaidya Sala, herb garden- 2009 Kerala. Aryavaidsala, Page no: 44, Pp 525

5. C.Alagesaboopathi, Journal of Pharmacy Research 2012,5(12),5248-5252

6. Sharangadharacharya, Sharagadhara Samhita, Commentator- Adhamalla and Kasirama, Reprint edition 2012, Chaukambha orientalia, Varanasi, Pg no.144 Pp. 397

\section{Source of Support: Nil Conflict of Interest: None Declared}

How to cite this URL: Ranjitha S \& Chandrakanth Bhat: An Experimental Evaluation Of Andrographis Macrobotrys Nees., A Folk Medicinal Plant For Analgesic Action In Wistar Albino Rats And Swiss Albino Mice- In Vivo Study. International Ayurvedic Medical Journal \{online\} 2021 \{cited August 2021\} Available from: http://www.iamj.in/posts/images/upload/1688_1697.pdf 